\title{
ArcheoSciences
}

Revue d'archéométrie

33 (suppl.) | 2009

Mémoire du sol, espace des hommes

\section{Tomographic Imaging of Ancient Wall Foundations in Thessaloniki, North Greece}

Panagiotis Tsourlos and Gregory N. Tsokas

\section{OpenEdition}

1 Journals

Electronic version

URL: https://journals.openedition.org/archeosciences/1865

DOI: 10.4000/archeosciences. 1865

ISBN: 978-2-7535-1599-4

ISSN: 2104-3728

Publisher

Presses universitaires de Rennes

Printed version

Date of publication: 30 October 2009

Number of pages: $371-373$

ISBN: 978-2-7535-0943-6

ISSN: 1960-1360

\section{Electronic reference}

Panagiotis Tsourlos and Gregory N. Tsokas, "Tomographic Imaging of Ancient Wall Foundations in Thessaloniki, North Greece", ArcheoSciences [Online], 33 (suppl.) | 2009, Online since 30 October 2011 connection on 21 September 2021. URL: http://journals.openedition.org/archeosciences/1865 ; DOI: https://doi.org/10.4000/archeosciences.1865 


\title{
Tomographic Imaging of Ancient Wall Foundations in Thessaloniki, North Greece
}

\author{
P. Tsourlos* and G. N. Tsokas*
}

Key words: ERT, cross borehole, Thessaloniki, Medieval wall, resistivity tomography.

\section{INTRODUCTION}

A survey involving both surface and cross borehole Electrical Resistivity Tomographies (ERTs) is described. It was conducted at various parts of the western wall of the city of Thessaloniki (N. Greece) aiming to estimate the extent of the walls' foundations.

The Thessaloniki city walls have been initially erected during the Hellinistic and early Roman period. A second phase, which is partly preserved until today, was build during the Byzantine period. It runs parallel to the older one and at parts the two walls coincide. It had an average height of 10 meters and a thickness of $4.5 \mathrm{~m}$. The wall is founded within alluvium sediments mostly clays and sands.

The present study was undertaken in the framework of the construction of the new Thessaloniki Underground, since the planned Metro line crosses the walls (Fig. 1) and the scheduled Metro station. Because of the urban environment, extensive use of surface geophysical methods was not possible. To complement the data and infer more safe conclusions, two pairs of boreholes were drilled and instrumented to obtain cross-hole ERT data.

\section{SURFACE ERT MEASUREMENTS}

Surface ERT measurements were carried out at lines crossing the wall over selected areas in which the wall has partly collapsed or is completely covered by pavement (pro-

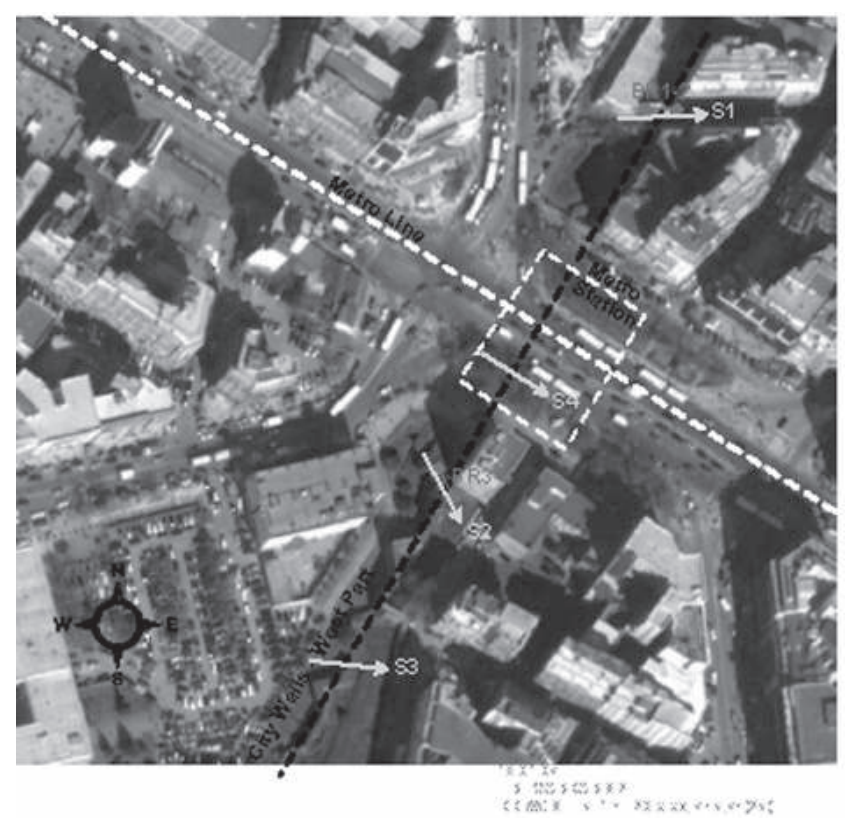

Figure 1 (see color plate): Photo showing the location of the Walls, the boreholes and the surface ERT lines.

files S1-S4 in Fig. 1). Measurements were obtained using the pole-dipole and the Wenner Schlumberger arrays using 24 electrodes spaced $1 \mathrm{~m}$ apart. Since the topography was rough, terrain had to be included into the inversion procedure. Bentonite and flat base electrodes were used in combination with conventional spike electrodes to avoid damaging the antiquities and the pavement (Athanasiou et al., 2007; Tsokas et al., 2008).

* Exploration Geophysics Lab., School of Geology, Aristotle University of Thessaloniki, 54124 Thessaloniki, Greece. 
The surface ERT measurements were processed using a smoothness constrained inversion algorithm (Tsourlos, 1995) and the inversion results are depicted in Figure 2. The RMS errors were particularly low $(<4 \%)$ indicative of the generally good data quality. The wall signature is depicted clearly as high resistivity anomaly in all sections. In sections S2 and S3 the wall's foundation seems to be reaching at depths of 4-5 $\mathrm{m}$ below ground level.

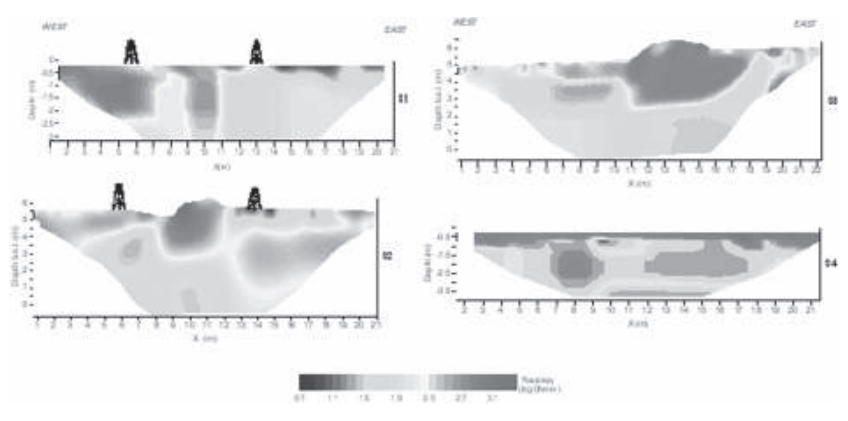

Figure 2 (see color plate): Inversion results of sections S1-S4 (see Fig 1 for location).

\section{Borehole ERT MEASUREMENTS AND INTERPRETATION}

Two pairs of typical geotechnical boreholes (B1-2 and B3-4 in Fig. 1) having an approximate length of $15 \mathrm{~m}$ were drilled and instrumented. The distance between the holes was approximately $7 \mathrm{~m}$ and the inter-electrode spacing was set to $0.5 \mathrm{~m}$ using 24 electrodes in each hole. The borehole cable was custom made by assembling 24 standard PVC coated $0.5 \mathrm{~mm}$ cooper conductors of variable length.

A thin plastic pipe was lowered into the hole and the cable was simultaneously attached to the pipe using tag tapes. Every 0.5 meters the pipe lowering procedure was stopped in order to attach an electrode which was an aluminium tag tape $(2 \mathrm{~cm}$ width) which encircled the pipe. At a final stage the hole was filled by a mixture of water, sand and bentonite. Finally a connector was fitted to every conductor (channel) and through a specially constructed box and connection cables; it was possible to connect the conductors to the automated resistivity instrument's switch box.

For every borehole pair several cross-hole ERT data sets employing the dipole-dipole, pole-pole and pole-dipole arrays were collected. Although, using also surface electrodes would be desirable, it was not made possible at the current state due to technical reasons. Given however that the ERT cable installation is permanent, this was left to be done in the near future.
Generally contact resistances were low $(<0.5 \mathrm{kOhm})$ and data repeatability using reciprocal measurement tests was excellent. The data sets were inverted using a smoothness constrained algorithm (Tsourlos, 1995) and the RMS errors were generally below $3 \%$. The inversion results of the crossed dipole-dipole array are presented here.

In Figure 3 (left hand side), the inversion results for the set obtained from boreholes B1-B2 is shown. In this particular area there are two walls as it was seen by an open excavation near-by and the respective surface ERT S1 (Fig. 2): to the left the "newest" Byzantine wall while to the centre the classical wall. High resistivity areas at the central part correspond to the "classical" wall and it seems that its foundations reach to the depth of 6 meters being in agreement with what the archaeologists were expecting.

Figure 3 (right hand side) shows also the inversion results for the tomography across the boreholes B3-B4. The high resistivity area at the central part is the wall's foundations. Note that in this case the Byzantine and classical walls coincide. The foundations of the wall seem to extend at a depth of approximately $5 \mathrm{~m}$ below the ground level. This result is in very good agreement with the respective surface ERT results (see section S3 in Fig. 2), regarding both the actual size and depth extent of the wall as well as regarding other features such as the resistive top layer to the left of the wall.

\section{Conclusions}

The use of combined tomographic methods to asses the depth of the wall foundations can produce reliable results in a situation where excavation is not possible. The borehole
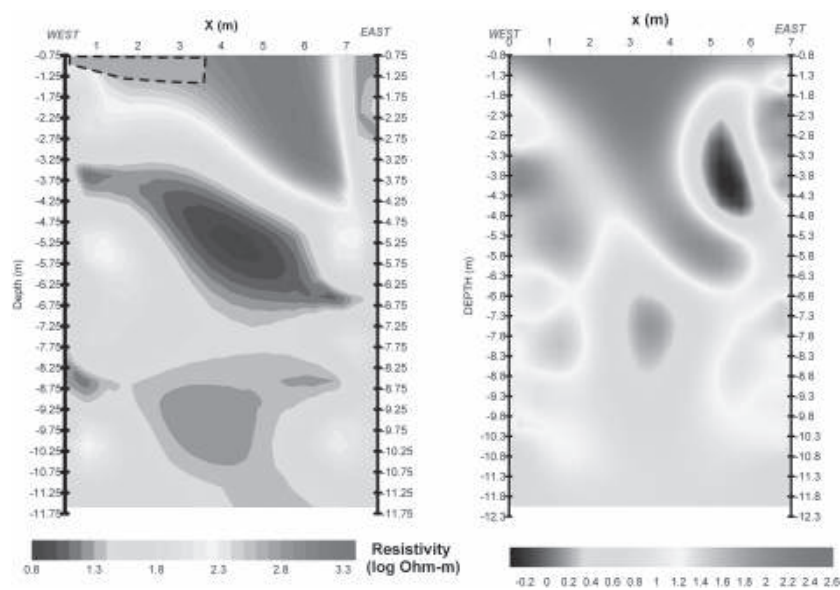

Figure 3 (see color plate): Inversion results of ERT B1-B2 (left) and ERT B3-B4 (right) 
ERTs results are in agreement with the existing information and the conventional surface ERTs.

\section{References}

Athanasiou, E., Tsourlos, P. I., Vargemezis, G., Papazachos, C. B., TsокаS, G. N., 2007. Nondestructive DC resistivity surveying using flat-base electrodes. Near Surface Geophysics, 5 (4): 243-272.
TsourLos, P., 1995. Modelling interpretation and inversion of multielectrode resistivity survey data. Ph.D. Thesis, University of York.

Tsokas, G. N., Tsourlos, P. I., Vargemezis, G., Novack, M., 2008. Non destructive ERT for indoors investigations: the case of Kapnikarea Church in Athens. Archaeological Prospection, 15: 47-61. 